\title{
Microwave heating as a novel route for obtaining carbon precursors from anthracene oil
}

G. Predeanu1, S. M. Axinte ${ }^{2}$, M. F. Drăgoescu², Z. González ${ }^{3 *}$, P. Álvarez ${ }^{3}$, M. Granda ${ }^{3}$, R. Menéndez $^{3}$, A. Fiti ${ }^{2}$, B. Acevedo ${ }^{4}$, S. Melendi-Espina ${ }^{4}$, G. Gryglewicz ${ }^{5}$, J.J. Fernández ${ }^{6}$, V. Slăvescu ${ }^{1}$

${ }^{1}$ University Politechnica of Bucharest, Bucharest, Romania

${ }^{2}$ Claudiu Top Rom SRL, Bucharest, Romania

${ }^{3}$ Instituto Nacional del Carbón (INCAR-CSIC), Oviedo, Spain

${ }^{4}$ University of East Anglia (UEA), Norwich, UK

${ }^{5}$ Politechnika Wroclawska, Wroclaw, Poland

${ }^{6}$ Industrial Química del Nalón, S.A., Trubia, Spain

\section{Abstract}

This work describes a novel route for the preparation of pitches by oxidative polymerization of an industrial anthracene oil (AO) in a microwave semi-pilot equipment consisting in a multimode applicator having a $2.45 \mathrm{GHz}$ magnetron with variable microwave power. The experimental five variables of microwave heating of $\mathrm{AO}$ air-blowing range between $320-380{ }^{\circ} \mathrm{C}$ (temperature), $0.2-3.9{ }^{\circ} \mathrm{C} \min ^{-1}$ (heating rate), $1.5-5 \mathrm{~h}$ (soaking time), $16-20.5 \%$ (air/AO ratio ) and $200-1500 \mathrm{~g}$ (initial weight). Their effect on the overall microwave air-blowing process is evaluated by means of a statistical analysis. A detailed characterization of the pitches has been carried out in terms of ultimate analysis, softening point, solubility parameters (toluene insolubles (TI) and quinoline insolubles (QI)) and thermogravimetric analysis. The experiments were also carried out by using conventional heating for comparative purposes. The detailed study of the electric energy consumption of the overall microwave treatment allows estimating a significant electric energy saving of about $20 \%$ when compared to conventional heating thus representing an excellent result in the production of carbon precursors.

Keywords: microwave heating, conventional heating, anthracene oil-based pitches, oxidative polymerization, carbon precursor, energy consumption

\section{* Corresponding author: Zoraida González}

E-mail address: zoraidag@ incar.csic.es 


\section{Introduction}

Anthracene oil (AO) is a tar fraction that distils between 250 and $370{ }^{\circ} \mathrm{C}$. This fraction mainly consists of polycyclic aromatic hydrocarbons (PAHs) of 3-5 rings, which can be transformed into a pitch by oxidative thermal condensation [1,2]. The conversion of AO into pitch is performed by conventionally thermal treatment in the presence of air (or oxygen) by using a traditional electrical device (e.g. reactor, autoclave, etc.). Briefly, the oxidative thermal condensation consists on the reaction of PAHs with oxygen, forming free radicals able to react among them giving rise to larger PAHs [3]. These polymerization reactions take place by the input of energy provided by thermal heating, which in turn is supplied by the above mentioned electrical device. However, this energy could be provided in other ways.

Microwave heating is an unconventional heating alternative, based on conversion of electromagnetic (EM) energy into heat depending on the type of interaction with the targeted materials. Furthermore, the heating of a material in microwave field depends on its dielectric and magnetic properties as the electric and magnetic fields interact with the material during irradiation [4].

Several advantages can be cited when using microwaves as the heating source: (1) localized heating allowing higher heating rates and shorter processing times; (2) selective heating with smaller heat loss; (3) possibility of energy saving, once it is used to directly heat the reaction mass; (4) possibility of using a commercially available and relatively compact device; (5) switching speed to start and stop; (6) precise process control, as the most of the available equipments allow the monitoring of different experimental parameters $[5,6]$.

A microwave oven is mainly composed of a microwave source (magnetron which is used to generate long microwaves) with the power supply and control, connected to a transmission line (waveguide for higher power, coaxial cables for lower power), transmitting electromagnetic energy into a metallic cavity (commonly called applicator) into which the reactor is inserted [7]. The geometry of the cavity can adopt various forms, depending on the process to be carried out. When the microwaves are injected into the cavity, the metal walls generate reflections of well-known phenomenon of interference, characterized by the low field strength alternating with high-intensity positions.

The main difference between conventional and microwave heating is the way in which heat is generated. In conventional processing, energy is transferred to the material through convection, conduction and radiation of heat from its surface [8]. In contrast, further studies have showed 
that microwave energy is led directly to the material through molecular interactions with the electromagnetic waves being transformed into heat inside the particles by dipole rotation and ionic conduction. The main benefit of using microwave heating is that the treatment time can be considerably reduced, which in many cases also represents a reduction in the energy consumption. The uniqueness of the microwave treatment is to process materials with selective energy, higher rate, uniform heating of any absorbing microwave material and energy conservation [9-12]. There are a wide range of microwave equipments for different chemical or biochemical applications, including single or multiple-mode microwave cavity, with temperature measurement devices including K-type metallic thermocouples, pyrometers, with flux of different gases and electronic balance.

In the last 65 years, the unconventional processing of materials by microwave heating become popular due to potential advantages over the conventional techniques. Since its first application for cooking [13], microwaves have been used for many purposes, including chemical synthesis of organic and inorganic substances, industrial processes, biosciences, food industry and environmental treatments among others [14-24].

Recently, microwave energy has been widely used in a large number of applications and different processing levels from laboratory to industrial scale. There are publications which describe the use of microwaves for carbonization of different carbon precursors $[9,25,26]$, activation and regeneration trials [27-29] as well as for the modification of the surface chemistry of activated carbon fibers [23] having positive influence on the characteristics of the final products [30,31]. In addition, the production of micro-mesoporous activated carbons for high performance supercapacitors [32-34], graphene oxide-carbon nanotube composites as negative electrode materials for lithium ion batteries [35-37], graphitic carbon [38,39] and nitrogen-doped hollow carbon spheres with high monodispersity [40] have been also reported.

This paper reports on the preparation of pitches by the air-blowing of an industrial AO. As a novelty, the process was performed in a semi-pilot microwave equipment and the effect of the experimental variables on the properties of the AO-based pitches obtained has been studied. Moreover, a detailed characterization of selected microwave-derived $\mathrm{AO}$ pitches has been carried out in order to compare them with AO pitches prepared by conventional thermal heating. Of particular interest has been the detailed study of the energy consumption of the overall microwave treatment which allows estimating a significant energy saving when compared to conventional heating thus representing an excellent result in the production of carbon precursors. 


\section{Experimental}

\subsection{Raw material}

A commercial anthracene oil (AO) supplied by Industrial Química del Nalón S.A (Asturias, Spain), was used as raw material.

\subsection{Oxidative polymerization of anthracene oil by microwave heating}

Oxidative polymerization of $\mathrm{AO}$ was carried out in a specifically designed microwave equipment (Fig. 1). It mainly consists on a multi-mode applicator having a quartzreactor with a total capacity of $2000 \mathrm{~mL}$. At the top there is a lid with three necks: one for air cooled reflux condenser, one for thermocuple, and one for a glass tube (3 $\mathrm{mm}$ in diameter) which assured air/inert gas inlet into the sample, and thus allowed the continuously sample mixing by gas bubbling. Since the dielectric constant and the penetration depth of microwaves into the reaction mass of $\mathrm{AO}$ were not determined, this equipment was also equipped with an impedance tuner, devices for measuring direct microwave power $\left(\mathrm{P}_{\text {direct }}\right)$ and reflected microwave power $\left(\mathrm{P}_{\text {reflected}}\right)$, water load or sliding short circuit, an infrared temperature sensor and a microwave-power controller system. Multi-mode applicator was chosen because electric field has a known configuration and $\mathrm{AO}$ can be placed in its maximum field of the microwave. In order to prevent evaporation of low weight $\mathrm{AO}$ components, an air-cooled reflux condenser was placed on the top of the quartz reactor.
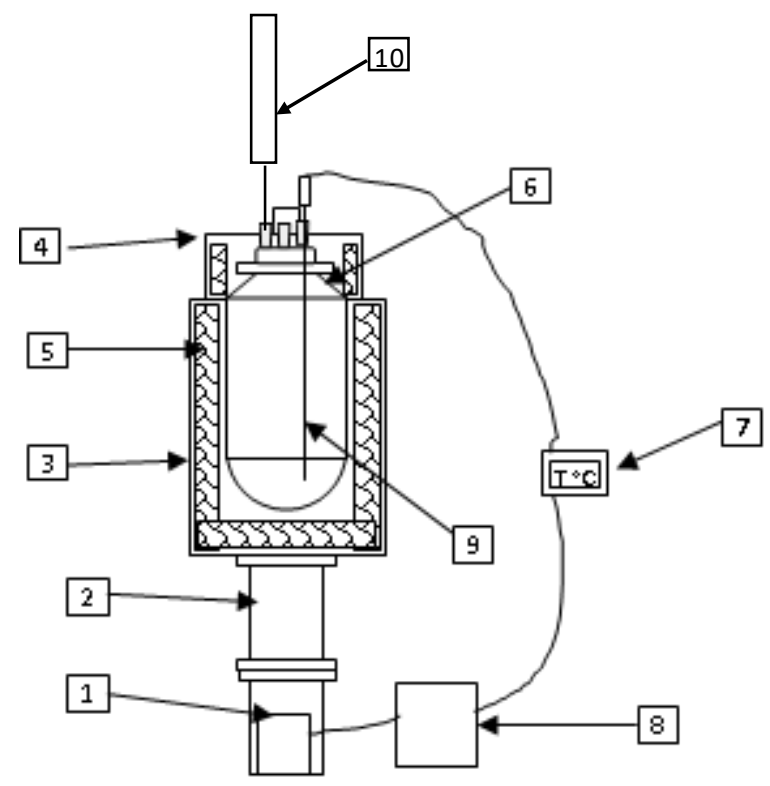
Fig. 1. Schematic diagram of the multi-mode experimental microwave reactor (1. Microwave generator, 2. Waveguide; 3. Applicator; 4. Lid; 5. Thermal insulation; 6. Quartz reactor; 7. Temperature controler; 8. Power controller system; 9. Thermocouple, 10. Condenser system).

Each run was defined by five different technological variables summarized in Table 1. In a typical run, the desired amount of AO was placed in the microwave oven. AO was heated from room temperature to the desired final temperature $\left(320-380{ }^{\circ} \mathrm{C}\right)$ with the selected heating rate. For this purpose, $2.45 \mathrm{GHz}$ frequency was used. Once reached the final temperature, the system was maintained for the desired soaking time. Once the reaction was finished the system was allowed to cool down to room temperature. From all the pitches obtained, three were selected for further characterization, labelled as MWP-71, MWP-92 and MWP-221 in correspondence with their softening points (see Supporting Information (SI) for details).

Table 1. Operational ranges of the technological variables used in the oxydative polymerization of anthracene oil (AO) in a microwave semi-pilot equipment.

\begin{tabular}{|c|c|c|}
\hline Technological variables & Limit Min. & Limit Max. \\
\hline $\begin{array}{l}\text { Maximum temperature of } \\
\text { the treatment }\left(\mathrm{T}_{\operatorname{Max}},{ }^{\circ} \mathrm{C}\right)\end{array}$ & 320 & 380 \\
\hline Heating rate $\left({ }^{\circ} \mathrm{C} \min ^{-1}\right)$ & 0.2 & 3.9 \\
\hline Soaking time (h) & 1.5 & 5 \\
\hline Air /AO ratio ${ }^{1}(\%)$ & 16 & 20.5 \\
\hline Initial weight (g) & 200 & 1500 \\
\hline
\end{tabular}

\subsection{Statistical analysis}

A multiple regression linear analysis was conducted to estimate the oxidative polymerization of AO by microwave heating using the Statgraphics software. The five technological factors were used as variables. As responses, the pitch yield and its toluene insoluble content (TI) were selected. The experimental desing was achieved by means of an aleatory selection of twelve (12) runs in which the operiational variables were fixed (see S.I., for details).

The adjustment was optimized via the Cochrane-Orcutt model which allowed since least square lower regression coefficients [41].

\subsection{Oxidative polymerization of anthracene oil by conventional thermal treatment}


For comparative purposes $\mathrm{AO}$ was also treated by conventional heating, using an electrical oven (Fig. 2). In brief, the experimental device consists on a laboratory oven of 1,500 W which works up to $800{ }^{\circ} \mathrm{C}$ via an auto-transformer able to ensure variations between 0 and $220 \mathrm{~V}$ under a maximum current intensity of $8.5 \mathrm{~A}$. On the route command an electric panel was inserted, on which the values of electrical load and temperature can be tracked simultaneously.

The parameters used for conventional oxidative thermal treatment of $200 \mathrm{~g}$ of AO were: a reaction temperature of $340{ }^{\circ} \mathrm{C}$; air/AO ratio of $27 \%$, a heating rate of $2{ }^{\circ} \mathrm{C} \min ^{-1}$ and a soaking time of $2 \mathrm{~h}$. Under these conditions, TTP-140 was obtained (name in reference to the softening point of that pitch).

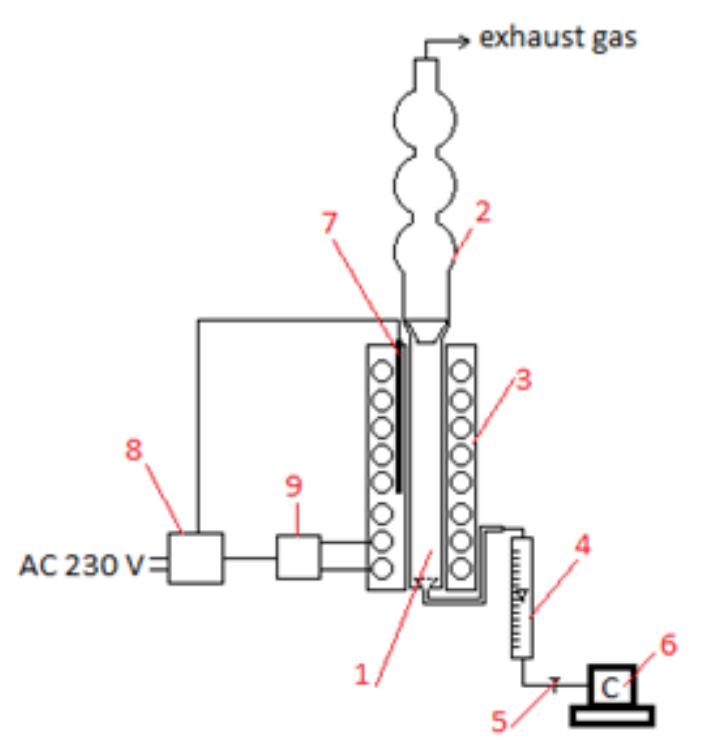

155

156

157

158

159

160

161

\subsection{Characterization of the pitches}

\subsubsection{Elemental analysis}

The carbon and hydrogen content of the samples was determined by elemental analysis with a LECO-CHNS-932 microanalyzer. The oxygen content was ascertained directly using a LECOVTF-900 furnace coupled to the microanalyzer. The analyses were performed using $1 \mathrm{mg}$ of ground sample. The results were quoted from an average of the values of four determinations. In all cases, the experimental error was $<0.5 \%$ of the absolute value.

\subsubsection{Softening point}


The softening point (SP) of the pitches was determined using a Mettler Toledo instrument adopting the ASTM D-3104-97 Standard.

\subsubsection{Solubility parameters}

The solubility of the samples in toluene (determined as toluene insoluble fraction, TI) and quinoline (determined as the quinoline insoluble fraction, QI) was detemined according to Pechiney B-16 (series PT-7/79 of STPTC) Standard and ASTM D2318-16 Standard, respectively.

\subsubsection{Thermogravimetric analysis}

Thermogravimetric analyses (TG/DTG) were carried out in a thermobalance TA Instruments SDT 2960, using 15-20 mg of sample (particle size $<0.4 \mathrm{~mm}$ ) placed in a platinum crucible and heating at $10{ }^{\circ} \mathrm{C} \mathrm{min}^{-1}$ to $1000{ }^{\circ} \mathrm{C}$ in a nitrogen flow of $100 \mathrm{~mL} \mathrm{~min}-1$.

\section{Results and discussion}

\subsection{Oxidative polymerization of anthracene oil by microwave heating}

AO was polymerized by using the micorwave device depicted in Fig. 1. After setting the working temperature, the heating process was conducted by means of a monophasic auto transformer. This allowed controlling magnetron tension involved in assuring microwave power. A graduated increase of the microwave power prevented AO overheating. The device was designed to optimize the five technological variables more relevant for the process (i.e. maximum temperature of the treatment, heating rate, soaking time at maximum temperature, air/AO ratio and initial weight of $\mathrm{AO}$ ) which operate in the ranges summarized in Table 1 . To estimate the complex effects of the five factors at the same time on the overall microwave airblowing process, a statistical analysis of multiple regression was carried out in the range of factor studied [41]. Two properties of the pitches were selected as responses for this analysis. These are the yield of the pitch after the experiment, which is the main factor defining the overall yield of the preparation procedure, and the toluene insoluble content of each pitch (TI, \%), which is a measurement of the intrinsic properties of the pitch, in this case, of the polymerization degree of its components [42-44]. 
199

200

201

202

203

204

205

206

207

208

209

210

211

212

213

214

215

216

The fiability of the statistical empirical model for each response is shown in Equations (I) and (II). The coefficient of determination, $\mathrm{R}^{2}$, was 0.816 for pitch yield and 0.812 for TI (see SI for details).

Additionally, the model equations were evaluated by the F-test ANOVA. The analysis of variance (ANOVA), with Prob > $\mathrm{F}^{*}$ of 0.0019 for pitch yield and of 0.0021 for TI (both values $<0.05)$ confirms the significance of the methodology applied. The results summarizing the significance of the variables are depicted in SI for details. This analysis also indicate the significant microwave technology features which mostly affect each response studied. These are the initial weight of AO loaded in the microwave reactor, the air flow and the heating rate used for pitch yield (\%) and only the initial weight and the air flow for TI (\%). It should be noted that the critical effect caused by the initial weight in the microwave reactor can be understood by considering a resonant cavity in the microwave field. The variation of the amount of AO subjected to radiation involves a change in shape of the electric field which ensures the heating. In addition, by increasing the thickness of the sample located in the electric field, an increase in the number of polar oriented molecules is expected, thus enhancing the probability of efficient collisions favorable to the development of chemical reactions among AO components $[45,46]$. On the other hand, the air flow controlles the (vapor/liquid) level at equilibrium which should be maintained for all runs thus limiting the ratio to be used.
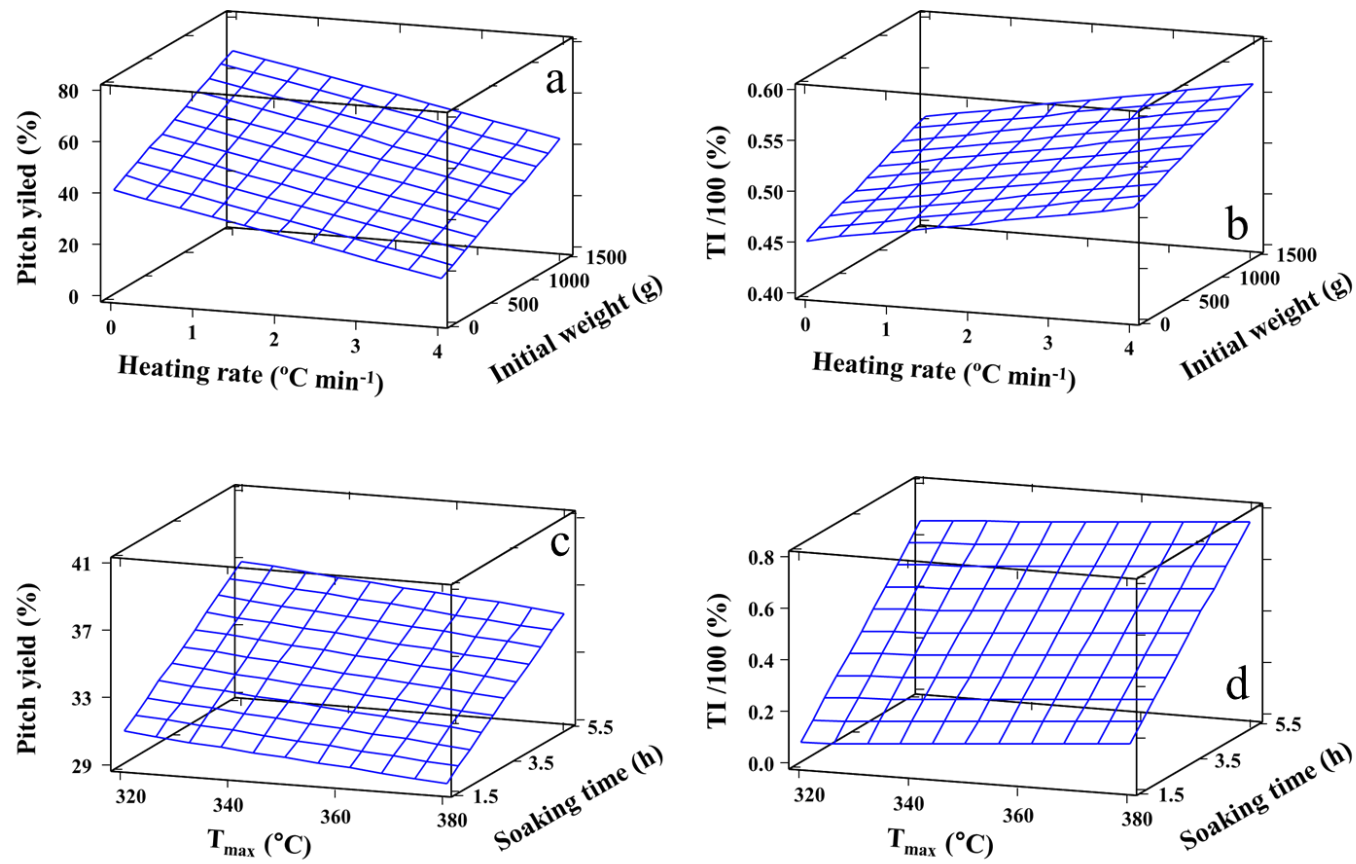

217

Fig. 3. Response surface plots showing the effect of $a, b)$ heating rate and initial AO weight at 219 fixed conditions of $T_{\max }$ of $360^{\circ} \mathrm{C}$, air/AO ratio20.5\% and soaking time of 4 h for pitch yield (a) 
and toluene insolubles $(b) ; c, d) T_{\max }$ and soak time at fixed conditions of heating rate of $2.5{ }^{\circ} \mathrm{C}$ $\mathrm{min}^{-1}$, air/AO ratio $20.5 \%$ and $400 \mathrm{~g}$ of AO loading for pitch yield (c) and toluene insolubles (d).

It is possible to easily visualize the estimated effect of the two factors mainly affecting each response by means of the corresponding $3 \mathrm{D}$ response surface plots. To construct the plots the other three factors must be fixed. As an example, and considering the factors most affecting the variables previously discussed, Fig. $3 \mathrm{a}$ and $3 \mathrm{~b}$ shows the variations of pitch yield and $\mathrm{TI}$, respectively, with the heating rate and the initial weight at the conditions arbitrary fixed at $\mathrm{T}_{\max }$ of $360{ }^{\circ} \mathrm{C}$, air/AO ratio $20.5 \%$ and soaking time of $4 \mathrm{~h}$. Results indicate that, at these conditions, higher AO loadings in the microwave reactor increase both the pitch yield and the TI content, which confirms the previous assumptions. The effects are however less pronounced in the case of TI. The results also indicate that an increment in the air flow increases the pitch yield but contributes to decrease the toluene insoluble content. This opposite tendency could be related with the complexity of the polymerization mechanism of the AO components with air that could produce an initial aggregation of cross-linked molecules but with no great increase of their overall molecular weight [1].

The variation of the pitch yield (Fig. 3c) and TI (Fig. 3d) with the $\mathrm{T}_{\max }$ and soaking time (two of the known factors affecting the polymerization process itself) were also investigated for an arbitrary fixed conditions of heating rate of $2.5^{\circ} \mathrm{C} \mathrm{min}-1$, air/AO ratio $20.5 \%$ and $400 \mathrm{~g}$ of AO loading. At these conditions it is observed that the pitch yield decreases with the $\mathrm{T}_{\max }$ applied while rapidly increases at higher soaking times. This tendency is expected considering that longer reaction times favour the polymerization of the AO components. On the other hand, higher temperatures could also favour polymerization, but it also favours the elimination of larger volatiles with the overall tendency observed. This seems to be corroborated analysing the TI content for the same conditions (Fig. 3d) showing that an increment of both, the $\mathrm{T}_{\max }$ and soaking time increases the TI content (ascribed to highly polymerized pitch) [42-44].

\subsection{Properties of the microwave and thermally treated pitches}

It is also important to determine wheather the properties of the microwave-based anthracene oil pitches obtained by this new technology are comparable to the standard AO pitch obtained by conventional hetaing.

The pitches under study were characterized by means of elemental analysis, quinoline insoluble content and softening point (Table 2). 
Table 2. Processing conditions used for the preparation of pitches by microwave heating (MWP-

Series) and conventional thermal treatment (TTP-Series) and pitch characteristics.

\begin{tabular}{|c|c|c|c|c|c|c|c|c|c|c|}
\hline \multirow[b]{2}{*}{ Sample } & \multicolumn{3}{|c|}{ Processing conditions } & \multicolumn{7}{|c|}{ Pitch characteristics } \\
\hline & $\begin{array}{c}\text { Air/AO } \\
\text { ratio } \\
(\%)\end{array}$ & $\begin{array}{c}\mathbf{T}^{\mathbf{1}} \\
\left({ }^{\circ} \mathbf{C}\right)\end{array}$ & $\begin{array}{l}\mathbf{t}_{\mathbf{r}}^{2} \\
(\mathbf{h})\end{array}$ & $\mathbf{O}^{3}$ & $\mathbf{H}^{4}$ & $\mathrm{C} / \mathrm{O}^{5}$ & $\mathrm{C} / \mathrm{H}^{6}$ & $\mathbf{T I}^{7}$ & $Q^{8}$ & $\mathbf{S P}^{9}$ \\
\hline $\mathrm{AO}$ & - & - & - & 0.9 & 5.6 & 136.4 & 1.4 & 0.0 & 0.0 & - \\
\hline MWP-71 & 20.5 & 320 & 3.5 & 2.5 & 4.7 & 57.8 & 1.6 & 17.6 & 0.0 & 71 \\
\hline MWP-92 & 18.7 & 360 & 2.5 & 2.0 & 4.7 & 64.3 & 1.6 & 14.0 & 0.0 & 92 \\
\hline MWP-221 & 16.0 & 380 & 4.0 & 1.3 & 3.7 & 91.3 & 2.0 & 60.7 & 24.0 & 221 \\
\hline TTP-140 & 27.0 & 340 & 2.0 & 2.9 & 4.0 & 42.1 & 1.9 & 58.9 & 14.2 & 140 \\
\hline
\end{tabular}

255

256

257

258

259

260

261

262

263

264

265

266

267

268

${ }^{1}$ Reaction temperature, ${ }^{2}$ Soaking time, ${ }^{3}$ Oxygen content $(w t . \%),{ }^{4}$ Hydrogen content $(w t . \%),{ }^{5}$ Carbon/oxygen atomic ratio, ${ }^{6}$ Carbon/hydrogen atomic ratio, ${ }^{7}$ Toluene insoluble content (wt.\%), ${ }^{8}$ Quinoline insoluble content (wt.\%), ${ }^{9}$ Softening point $\left({ }^{\circ} \mathrm{C}\right)$

In general terms, pitches with the higest softening points (MWP-221 and TTP-140) exhibit higher QI and TI contents as a consequence of their higher polymerization degree. This is not the case of pitches with lower softening point since the TI content in MWP-92 (14.0 wt.\%) is lower than in MWP-71 (17.6 wt.\%). This fact can be, however, explained by considering competitive AO oxydation/polymerization mechanisms taking place at those milder experimental conditions (i.e. lower temperature of thermal treatment and lower soaking time).

When comparing the $\mathrm{O}$ content in the microwave-based pitches series, it is observed that an increase in the softening point (which was also obtained via higher temperatures) is accompanied by a decrease of their $\mathrm{O}$ content (from 2.5 wt.\% of $\mathrm{O}$ in MWP-71 to 1.3 wt.\% in MWP-221. What is more, the pitch obtained by conventional heating, exhibit the highest $\mathrm{O}$ content (2.9 wt.\%) despite having an intermediate softening point of $140{ }^{\circ} \mathrm{C}$. This clearly highligts that the microwave technology developed herein allows the preparation of polymerized anthacene oil based pitches incorporating a low amount of oxygen in its composition. 

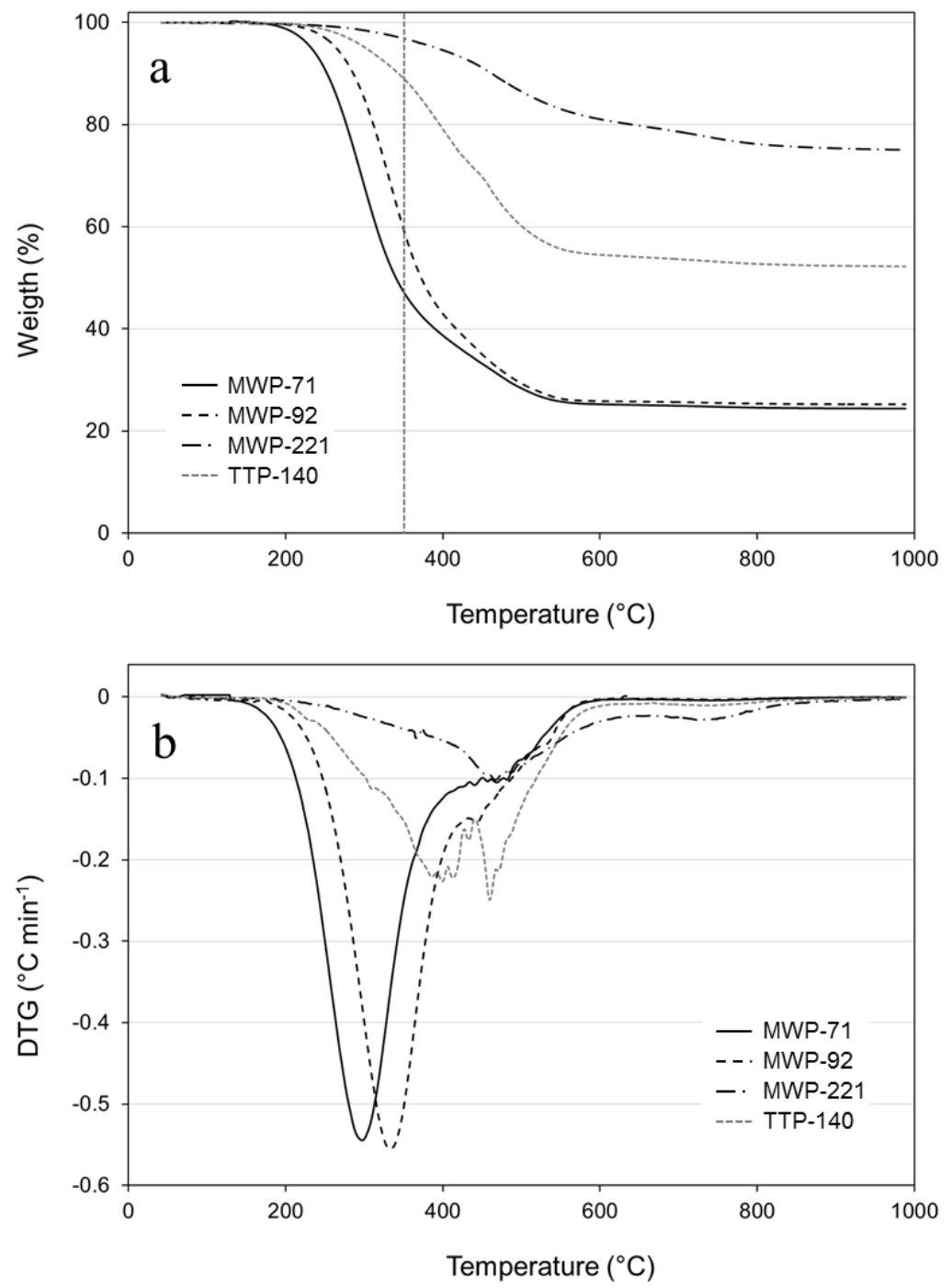
Table 3. Thermogravimetric parameters of the pitches.

\begin{tabular}{|c|c|c|c|c|}
\hline Sample & $\mathbf{T}_{\mathbf{i}}{ }^{1}$ & $T_{\operatorname{max1}}{ }^{2}$ & $\mathbf{R}_{350}{ }^{3}$ & $R_{1000}{ }^{4}$ \\
\hline MWP-71 & 196 & 297 & 47.2 & 24.4 \\
\hline MWP-92 & 222 & 333 & 59.5 & 25.2 \\
\hline MWP-221 & 273 & $400 / 460^{5}$ & 96.9 & 75.0 \\
\hline TTP-140 & 239 & $400 / 460^{5}$ & 89.1 & 52.2 \\
\hline
\end{tabular}

276

277 The pyrolysis behavior of the pitches, studied by thermogravimetric analysis, is mainly determined by their characteristics, which in turn are governed by the polymerization degree. The thermogravimetric results of the pitches under study are depicted in Fig. 4 and Table 3. A detailed quantification of weight loss by temperature ranges is summarized in Fig. 5.

For all the pitches, the initial temperature of weight loss (Fig. 4a) and the maximum temperature of weigh loss rate ( $T_{i}$ and $T_{\max }$ respectively, Table 3) increase at higher softening point of the pitches, as an indication of the direct relation of the softening point of the pitch with its polymerization degree.

Interestingly, MWP-71 and MWP-92 show a temperature of initial weight loss at 196 and 222 ${ }^{\circ} \mathrm{C}$, respectively, and a temperature of maximum rate of weight loss centered at 297 and $333{ }^{\circ} \mathrm{C}$, respectively. A thermogravimetric parameter of special relevance for determining the polymerization degree in $\mathrm{AO}$ is $\mathrm{R}_{350}$. This parameter is defined as the residue left by the sample at $350{ }^{\circ} \mathrm{C}$, which is zero in the case of AO [1]. The value of this parameter in AO-based pitches can be directly related with the amount of raw material (i.e. anthracene oil) that has been polymerized.

For MWP-71 and MWP-92 this parameter reaches values of 47.2 and 59.5 wt. \%, respectively and increses up to $89.1 \%$ for TTP-140 and $96.9 \%$ for MWP-221. This seems to reflect that the volatile content of these pitches has a great influence in their softening point. 


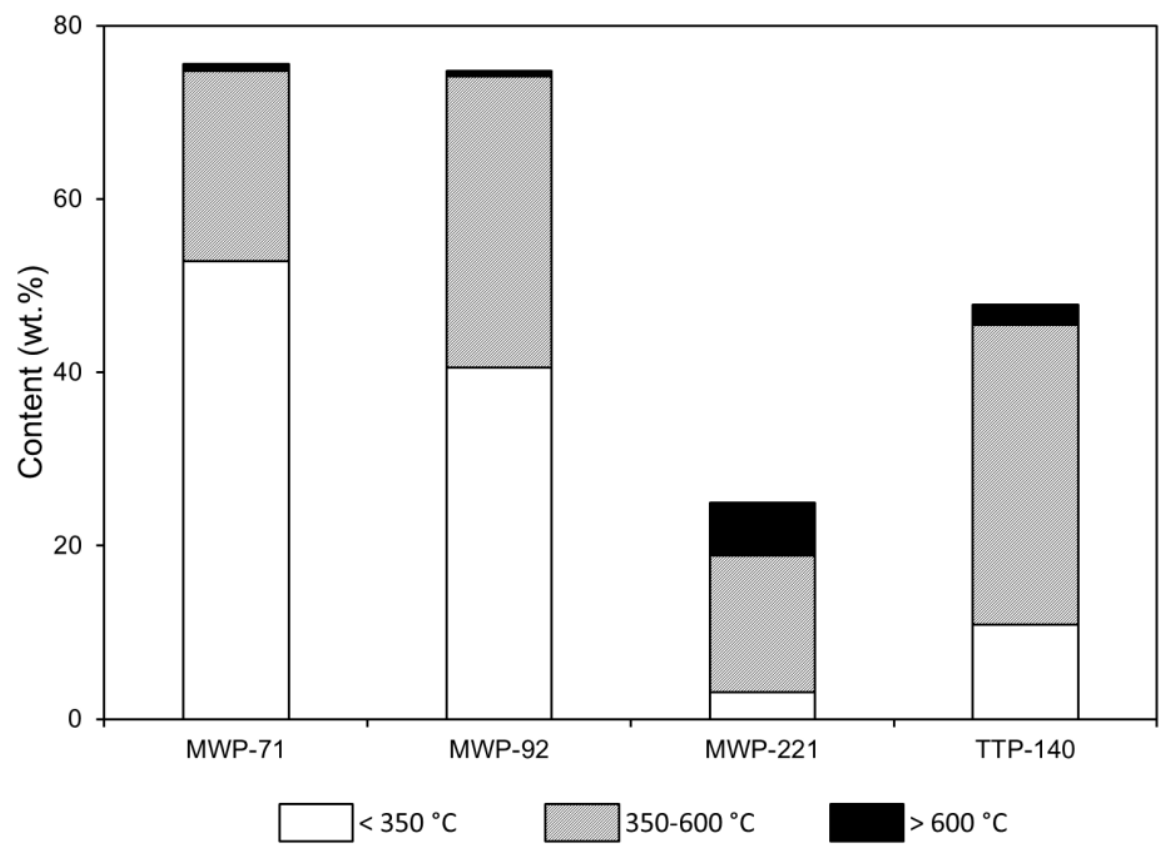

Fig. 5. Variation of weight loss in the temperature range of $<350{ }^{\circ} \mathrm{C}, 350-600{ }^{\circ} \mathrm{C}$ and $>600{ }^{\circ} \mathrm{C}$, 298 determined by thermogravimetric analysis for microwave-based pitches MWP-71, MWP-92 and MWP-221, and conventionally heated pitch TTP-140.

However, not all the polymerized AO components are consolidated during the subsequent carbonization. In a second temperature range, between $350-600{ }^{\circ} \mathrm{C}$, the weight loss is mainly due to AO components that, even having being polymerized, are distilled once their boiling point is reached due to their thermal instability (Fig. 5). Thus, although the polymerization degree of MWP-92 is greater than that of MWP-71 (lower weight loss below $350{ }^{\circ} \mathrm{C}$, Fig. 5), the thermal stability of their polymerized components is lower (higher weight loss in the temperature range of $350-600{ }^{\circ} \mathrm{C}$, Fig. 5) and it is only MWP-221 that the weight loss in this region decreases. The small molecules generated as a consequence of the complex reactions that take place during the thermal treatment in this temperature range (e.g. cracking, condensation, etc.) are also removed. It is only above $600{ }^{\circ} \mathrm{C}$, once the pitches have been progressed generating a solid green coke, that the weight loss is mainly attributed to the removal of small molecules related to the multiple reactions that take place at this high temperature (e.g., isomerizations, molecular rearrangements, etc.). In this region, low softening point pitches lose similar amount of weight 1 wt.\% (Fig. 5). In contrast, MWP-221 loses a 5.7 wt. \%. This result suggests that, in all cases, the oxidative treatment has caused a certain cross-linking between $\mathrm{AO}$ components and, consequently, some small molecules are removed due to the reactions that take place when the sample is already a solid (green coke). Moreover, the carbonaceous residue at $1000{ }^{\circ} \mathrm{C}$ for MWP- 
221 (75 wt. \%) evidence that in this pitch the degree of polymerization and the capacity of consolidation of the polymerized components is much greater than in the two previous ones.

320 It is important to remark that the pitch obtained by conventional thermal treatment (TTP-140) exhibits somehow an intermediate behaviour between MWP-92 and MWP-221 (pitches with intermediate softening points). It seems therefore that despite a different polymerization mechanism could be established at early stages of the AO polymerization, i.e. by using milder microwave reaction conditions, the use of more severe reaction conditions in the microwave oven minimizes the differences in the properties of the pitches obtained with respect to those obtained by conventional thermal treatment.

\subsection{Electric energy consumption during microwave and conventional heating}

Of particular importance is to evaluate the electric energy consumption of the AO polymerization which, in turn, will determine the feasibility of the microwave technology developed herein to produce AO-based pitches in competitive conditions to those required by using conventional heating. The study approached two thermal ranges, below $290{ }^{\circ} \mathrm{C}$ and over $290{ }^{\circ} \mathrm{C}$.

This temperature was selected as the threshold during the microwave studies, as, before the oxidative treatment, a distillation step was performed at $290{ }^{\circ} \mathrm{C}$ in order to reduce the influence of light fractions during the microwave heating behavior of $\mathrm{AO}$. The data of Table 4 come from the measurements made in the laboratory trials. 
Table. 4. Electric energy consumption for oxidative polymerization of $A O$ in microwave and conventional heating

\begin{tabular}{|c|c|c|c|c|c|c|}
\hline \multirow{2}{*}{\multicolumn{2}{|c|}{ Characteristic }} & \multirow[b]{2}{*}{ Unit } & \multicolumn{3}{|c|}{ Microwave-based pitches } & \multirow{2}{*}{$\begin{array}{c}\text { Conventional- } \\
\text { based pitch } \\
\text { TTP-140 } \\
\end{array}$} \\
\hline & & & MWP-71 & MWP-92 & MWP-221 & \\
\hline \multicolumn{2}{|c|}{ AO amount } & $\mathrm{g}$ & 200 & 400 & 200 & 200 \\
\hline \multirow{2}{*}{$\begin{array}{l}\text { Electric energy } \\
\text { consumption on } \\
\text { thermal stages }\end{array}$} & $<290^{\circ} \mathrm{C}$ & $\mathrm{Wh}$ & 247.4 & 267.5 & 204.6 & 2825.3 \\
\hline & $>290^{\circ} \mathrm{C}$ & $\mathrm{Wh}$ & 833 & 553 & 534 & 902 \\
\hline \multicolumn{2}{|c|}{ Total electric energy consumption } & Wh & 1080.4 & 820.5 & 738.6 & 3727.3 \\
\hline \multirow{2}{*}{$\begin{array}{l}\text { Percent of electric } \\
\text { energy } \\
\text { consumption on } \\
\text { thermal stages }\end{array}$} & $<290^{\circ} \mathrm{C}$ & $\%$ & 22.9 & 32.6 & 27.7 & 75.8 \\
\hline & $>290^{\circ} \mathrm{C}$ & $\%$ & 77.1 & 67.4 & 72.3 & 24.2 \\
\hline \multicolumn{2}{|c|}{ Microwave power density } & $\mathrm{W} / \mathrm{g}$ & 3.8 & 2.2 & 3.2 & - \\
\hline \multirow{2}{*}{$\begin{array}{l}\text { Electric power } \\
\text { consumption on } \\
\text { thermal stages }\end{array}$} & $<290^{\circ} \mathrm{C}$ & $\mathrm{W}$ & 192.4 & 148.6 & 181.8 & 1284.2 \\
\hline & $>290^{\circ} \mathrm{C}$ & $\mathrm{W}$ & 151.4 & 158 & 133.5 & 180.4 \\
\hline
\end{tabular}

340

341

Considering the concept of microwave power density, the average values for this parameter were: 3.8, 2.2 and 3.2 W/g for pitches MWP-71, MWP-92 and MWP-221, respectively. As heating from room temperature to $290{ }^{\circ} \mathrm{C}$ was performed with a low percent of electric energy consumption $(27.7 \%)$ the most of the electric energy consumption of the process was assigned to the polymerisation stages of the AO over $290{ }^{\circ} \mathrm{C}(72.3 \%)$. Therefore, calculations of electric energy consumption were made on each processing step related to chemical changes. As a result, when processing $100 \mathrm{~g}$ of each AO sample the average electric power consumptions calculated were of $151.4,158.0$ and $133.5 \mathrm{~W}$ under the experimental procedures followed for obtaining MWP-71, MWP-92 and MWP-140, respectively.

Although at a laboratory stage, these results present a proof of concept according to which the heating in microwave field provides benefits regarding the time of heat treatment and electric energy consumption. The average value of $147.6 \mathrm{~W}$ of electric power consumption in case of experiments carried out by microwave heating shows a decrease of about $20 \%$ compared to the electric power consumption of $180.4 \mathrm{~W}$ for conventional heating (Fig. 6). 
355 The experiments also confirmed the basic principles of microwave heating. Thus, energy is conducted directly to materials through molecular interactions and electromagnetic waves which are transformed into heat inside the particles, requiring a lower electric energy consumption of only $27.7 \%$ of the total electric energy in the preliminary phase of AO heating, up to the reaction temperature $\left(290{ }^{\circ} \mathrm{C}\right)$. During conventional heating according to which energy is transferred to material through convection, conduction and radiation of heat from its surface, $75.8 \%$ of the total electric energy is consumed in the preliminary phase of heating up to the reaction temperature $\left(290{ }^{\circ} \mathrm{C}\right)$ and the rest of $24.2 \%$ is used during polymerisation stages of $\mathrm{AO}$ (Fig. 6).

Fig. 6. Assesment of the total percent of electric energy consumption on thermal stages in case of microwave and conventional heating

Of course, this assessment is a preliminary one as between the conventional and microwave heating occure differences in the heating rate and the processes can not be currently compared step by step.

\section{Conclusions}

In this study, a microwave device was developed in order to perform, for the first time, the air-

377 blowing polymerization of $\mathrm{AO}$. 
The statistical analysis of the technological variables controlling the overall process reveals that two are the most important factors affecting the microwave heating: the initial weight of AO introduced, which has an influence on the shape of the electric field and in the number of polar oriented molecules, and the air flow used, which controlles the vapor/liquid level at equilibrium and should be maintained for all runs thus limiting the ratio to be used in the oven and the air flow.

A detailed analysis of the pitches properties allowed to determine that by controlling the experimental parameters during the microwave treatment, such properties, in terms of softening point or toluene insoluble content can be easily modulated. This is due to modifications of the mechanism involved, particularly at early stages of the polymerization reactions (milder experimental conditions). The properties of the microwave-based pithes are in any case in the range of those observed for pitches obtained by conventional thermal heating. This allows ensuring that the microwave technology developed herein is an attractive alternative to conventional thermal treatment for the air blowing of AO.

The analysis of the electric energy consumption of the overall process points out the benefits of the microwave technology when compared to the polymerization of AO by means of conventional thermal treatment. In this regard, this technology provides a significant electric energy saving, of about $20 \%$, thus representing an excellent result in the production of carbon precursors.

\section{Acknowledgements}

The research leading to these results has received funding from the European Union's Research Fund for Coal and Steel (RFCS) research programme under grant agreement RFCR-CT-201500006.

\section{References}

[1] Fernández AL, Granda M, Bermejo J, Menéndez R. Air-blowing of anthracene oil for carbon precursors. Carbon 2000; 38: 1315-1322.

[2] Bermejo J, Fernández AL, Granda M, Rubiera F, Suelves I, Menéndez R. Effects of thermal treatment on the composition and properties of air-blown anthracene oils. Fuel 2001;80:12291238. 
408 [3] Bermejo J, Menéndez R, Fernández AL, Granda M, Suelves I, Herod AA et al. A comparative study of the composition of anthracene oil polymerized by different treatments. Fuel 2001; 80: 2155-2162.

[4] Clark DE, Sutton WH, Microwave processing of materials. Annu Rev Mater Sci. 1996; 26:299-331.

[5] Leonelli C, Mason TJ. Microwave and ultrasonic processing: now a realistic option for industry, Chem Eng Process. 2010;49:885-900.

[6] Gabriel C, Gabriel S, Grant EH, Halstead BSJ, Mingos DMP. Dielectric parameters relevant to microwave dielectric heating. Chem Soc Rev. 1998;27:213-223.

[7] Lupi S. High frequency and microwave heating. In: Fundamentals of electroheat. Electrical technologies for process heat. Springer Int Publ Switzerland 2017; p. 583-603.

[8] Leonelli C, Veronesi P. Microwave reactors for chemical synthesis and biofuels preparation. In: Fang Z, Smith Jr RL, Qi X, editors. Production of biofuels and chemicals with microwave. Springer Netherlands 2015; p. 17-40.

[9] Yang SK, Yoon YJ, Lee MS, Lee WJ, Kim JH. Further carbonization of anisotropic and isotropic pitch-based carbons by microwave irradiation. Carbon 2002;40:897-903.

[10] Ania CO, Parra JB, Menéndez JA, Pis JJ. Effect of microwave and conventional regeneration on the microporous and mesoporous network and on the adsorptive capacity of activated carbons. Micropor Mesopor Mater 2005; 85 (1-2):7-15. [11] Nabais JMV, Carrott PJM, Carrott MMLR, Menendez JA. Preparation and modification of activated carbon fibres by microwave heating. Carbon 2004;42(7):1315-1320. [12] Jones DA, Lelyveld TP, Mavrofidis SD, Kingman SW, Miles NJ. Microwave heating applications in environmental engineering - a review. Resour Conserv Recy 2002;34(2):75-90.

[13] Osepchuk M. A history of microwave-heating applications. IEEE Trans. Microwave Theory Tech. 1984;32:1200-1224.

[14] Das S, Mukhopadhyay AK, Datta S, Basu D. Prospects of microwave processing: an overview, Bull Mater Sci. 2009;32:1-13.

[15] Hoogenboom R, Schubert US. Microwave-assisted polymer synthesis: recent developments in a rapidly expanding field of research. Macromol Rapid Commun. 2007;28:368-386.

[16] Kappe CO. Microwave dielectric heating in synthetic organic chemistry. Chem. Soc. Rev. 2008; 37:1127-1139.

[17] Mehtaa VP, Van der Eycken EV. Microwave-assisted C-C bond forming cross-coupling reactions: an overview. Chem Soc Rev. 2011;40:4925-4936. 
442 [18] Richter RC, Link D, Kingston HMS. Peer reviewed: microwave-enhanced chemistry. Anal 443 Chem. 2001; 73:30A-37A.

444 [19] Kochhar SP, Singh AP. Developments in microwave processing of materials. Asian J Chem. $445 \quad 2011 ; 23: 3307-3312$.

446 [20] Ku HS, Siores E, Taube A, Ball JAR. Productivity improvement through the use of 447 industrial microwave technologies. Comput Ind Eng. 2002;42:281-290.

448 [21] Mutyala S, Fairbridge C, Pare JRJ, Belanger JMR, Ng S, Hawkins R. Microwave 449 applications to oil sands and petroleum: a review, Fuel Process Technol. 2010;91:127-135.

450 [22] Sturm GSJ, Stefanidis GD, Verweij MD, Van Gerven TDT, Stankiewicz AI. Design 451 principles of microwave applicators for small-scale process equipment. Chem Eng Process. 452 2010;49:912-922.

453 [23] Yin CG. Microwave-assisted pyrolysis of biomass for liquid biofuels production. Bioresour. 454 Technol. 2012;120:273-284.

455 [24] De la Hoz A, Diaz-Ortiz A, Moreno A. Microwaves in organic synthesis. Thermal and non456 thermal microwave effects. Chem Soc Rev, 2005;34(2):164-178.

457 [25] Monsef-Mirzai P, Ravindran M, McWhinnie WR, Burchill P. Rapid microwave pyrolysis of 458 coal. Methodology and examination of the residual and volatile phases. Fuel 1995; 74(1):20-27.

459 [26] Undri A, Meini S, Rosi L, Frediani M, Frediani P. Microwave pyrolysis of polymeric 460 materials: Waste tires treatment and characterization of the value-added products. Journal of 461 Analytical and Applied Pyrolysis 2013;103:149-158.

462 [27] Holland KM. Producing active carbon using microwave discharge. US Patent 1994: US $463 \quad 5,364,821$.

464 [28] Norman M, Cha CY. Production of activated carbon from coal chars using microwave 465 energy. Chem Eng Commun 1994; 140(1):87:110.

466 [29] Li W, Peng J, Zhang L, Yang K, Xia H, Zhang S, Guo S. Preparation of activated carbon 467 from coconut shell chars in pilot-scale microwave heating equipment at $60 \mathrm{~kW}$. Waste 468 Management 2009;29:756-760.

469 [30] Yagmur E, Ozmak M, Aktas Z. A novel method for production of activated carbon from 470 waste tea by chemical activation with microwave energy. Fuel 2008;87:3278-3285. 471 [31] Menéndez JA, Arenillas A, Fidalgo B, Fernández Y, Zubizarreta L, Calvo EG, Bermúdez 472 JM. Microwave heating processes involving carbon materials. Fuel Processing Technology $473 \quad 2010 ; 91: 1-8$. 
474 [32] Calvo EG, Ferrera-Lorenzo N, Menéndez JA, Arenillas A. Microwave synthesis of micromesoporous activated carbon xerogels for high performance supercapacitors. Microporous and Mesoporous Materials 2013;168:206-212. [33] He XJ, Li, XJ, Wang XT, Zhao N, Yu MX, Wu MB. Efficient preparation of porous carbons from coal tar pitch for high performance supercapacitors. New Carbon Materials, 2014; 29(6):493-502.

[34] Wu MB, Li RC, He XJ, Zhang HB, Sui WB, Tan MH. Microwave-assisted preparation of peanut shell-based activated carbons and their use in electrochemical capacitors. New Carbon Materials 2015;30(1):86-91.

[35] Chen t, Pan L, Yu K, Sun Z. Microwave-assisted synthesis of reduced graphene oxidecarbon nanotube composites as negative electrode materials for lithium ion batteries. Solid State Ionics 2012;229:9-13.

[36] Bajpai R, Wagner HD. Fast growth of carbon nanotubes using a microwave oven. Carbon, 487 2015;(82):327-336.

[37] Odom MGB, Sweeney CB, Parviz D, Linnea P. Sill LP, Saed MA, Green MJ. Rapid curing and additive manufacturing of thermoset systems using scanning microwave heating of carbon nanotube/epoxy composites. Carbon 2017;120:447-453.

[38] Kim T, Jo C, Lim WG, Lee J, Lee J, Lee KH. Facile conversion of activated carbon to battery anode material using microwave graphitization. Carbon, 2016;104:106-111.

[39] Zhu FL, Yang Z, Zhao JP, Zhao X. Microwave assisted preparation of expanded graphite/sulfur composites as cathodes for Li-S batteries. New Carbon Materials 2016;31(2):199204.

[40] Aditya F, Arif AF, Kobayashi Y, Balgis R, Ogi T, Iwasaki H, Okuyama K. Rapid microwave-assisted synthesis of nitrogen-functionalized hollow carbon spheres with high monodispersity. Carbon 2016;107:11-19. [41] Pedroso GT, Silva-Mann R, Camargo ME, Russo SL. Applied multiple regression for autocorrelated sugarcane data. African Journal of Agricultural Research 2014; 9(10): 914-920. [42] Álvarez P, Granda M, Sutil J, Santamaría R, Blanco C, Menéndez R, Fernández JJ, Viña, JA. Preparation of Low Toxicity Pitches by Thermal Oxidative Condensation of Anthracene Oil. Environ. Sci. Technol., 2009;43 (21): 8126-8132. polymerization of anthracene oil to produce pitch using nuclear magnetic resonance. Fuel, 
507 [44] Álvarez P, Granda M, Sutil J, Menendez R, Fernández JJ, Viña JA, Morgan T J, Millan M, 508 Herod AA, Kandiyoti R. Characterization and Pyrolysis Behavior of Novel Anthracene Oil 509 Derivatives. Energy Fuels, 2008; 22 (6): 4077-4086.

510 [45] Kim T, Lee J, Lee KH. Microwave heating of carbon-based solid materials. Carbon Letters $5112014 ; 15(1): 15-24$.

512 [46] Kato T. Volume Editor. Liquid Crystalline Functional Assemblies and Their 513 Supramolecular Structures. 2008 Springer-Verlag Berlin Heidelberg, ISBN 978-3-540-77866-0. 514 
Microwave heating as a novel route for obtaining carbon precursors from anthracene oil G. Predeanu1, S. M. Axinte², M. F. Drăgoescu², Z. González ${ }^{3 *}$, P. Álvarez ${ }^{3}$, M. Granda ${ }^{3}$, R. Menéndez $^{3}$, A. Fiti², B. Acevedo ${ }^{4}$, S. Melendi-Espina ${ }^{4}$, G. Gryglewicz ${ }^{5}$, J.J. Fernández 6 , V. Slăvescu ${ }^{1}$ 
546
Table S1. Technologycal variables involved in the Anthracene oil (AO) polymerization in microwave semi-pilot equipment.

\begin{tabular}{cccccc}
\hline \multirow{2}{*}{ Run } & \multicolumn{5}{c}{ Technological parameters /variables } \\
\cline { 2 - 6 } & $\mathbf{T}_{\mathbf{m a x}}{ }^{\mathbf{0}} \mathbf{C}$ & $\begin{array}{c}\text { Heating rate, } \\
\mathbf{}_{\mathbf{0}} \mathbf{C} \mathbf{~ m i n}^{-\mathbf{1}}\end{array}$ & $\begin{array}{c}\text { Soaking } \\
\text { time, } \mathbf{~}\end{array}$ & $\begin{array}{c}\text { Air flow, } \\
\mathbf{\%}\end{array}$ & $\begin{array}{c}\text { Initial Weight } \\
\mathbf{g}\end{array}$ \\
\hline $\mathbf{1}$ & 320 & 3.9 & 2.5 & 20.5 & 1468 \\
$\mathbf{2}$ & & 2.6 & 3 & & 1120 \\
\hline $\mathbf{3}$ & 320 & 2.6 & 3.5 & 20.5 & 215 \\
\hline $\mathbf{4}$ & 350 & 2.5 & 1.5 & 20.5 & 200 \\
\hline $\mathbf{5}$ & & 0.2 & 3 & 20.5 & 836 \\
$\mathbf{6}$ & & 2.6 & 3 & & \\
$\mathbf{7}$ & 350 & 2.6 & 3 & 27 & 300 \\
$\mathbf{8}$ & & 2.5 & 4 & & \\
$\mathbf{9}$ & & 2.5 & 5 & & 1329 \\
\hline $\mathbf{1 0}$ & 355 & 2.7 & 2 & 20.5 & 415 \\
$\mathbf{1 1}$ & 360 & 2.5 & 2.5 & 18.7 & 253 \\
$\mathbf{1 2}$ & 380 & 2.7 & 4 & 16 & \\
\hline
\end{tabular}

The obtained empirical models for each response are shown in Equations S1 and S2. The coefficient of determination, $\mathrm{R}^{2}$, was 0.816 for pitch yield and 0.812 for TI.

Pitch Yield $(\%)=0.25246-0.000263084 \times \mathrm{T}_{\max }-0.061988 \times$ Heating rate $+0.0150787 \times$ Soaking time $+0.00957137 \times$ Air flow $+0.000182847 \times$ Initial weight. $($ Eq. S1)

$\boldsymbol{T I}(\boldsymbol{\%})=0.124829+0.00156019 \times \mathrm{T}_{\max }+0.0141441 \times$ Heating rate $+0.147289 \times$ Soaking time $0.0392213 \times$ Air flow $+0.0000353341 \times$ Initial weight

(Eq. S2)

The model equations were evaluated by the F-test ANOVA. The results summarizing the significance of the variables are depicted in Table S2. 
Table S2. Analysis of variance (ANOVA) for the regression model

\begin{tabular}{|c|c|c|c|c|c|c|c|c|c|c|}
\hline \multirow[t]{2}{*}{ Factor } & \multicolumn{5}{|c|}{$\begin{array}{l}\text { Residue yield } \\
\left(R^{2}=0.816\right)\end{array}$} & \multicolumn{5}{|c|}{$\begin{array}{c}T I \\
\left(R^{2}=0.812\right)\end{array}$} \\
\hline & \multicolumn{3}{|c|}{ Standard Error } & \multicolumn{2}{|c|}{ Prob $>F^{*}$} & \multicolumn{3}{|c|}{ Standard Error } & \multicolumn{2}{|c|}{ Prob $>F^{*}$} \\
\hline$T_{\max }$ & \multicolumn{3}{|c|}{0.00107393} & \multicolumn{2}{|c|}{0.8114} & \multicolumn{3}{|c|}{0.893479} & \multicolumn{2}{|c|}{0.8917} \\
\hline HR & \multicolumn{3}{|c|}{0.0158273} & \multicolumn{2}{|c|}{0.0029} & \multicolumn{3}{|c|}{0.00231722} & \multicolumn{2}{|c|}{0.5160} \\
\hline ST & \multicolumn{3}{|c|}{0.0132935} & \multicolumn{2}{|c|}{0.2831} & \multicolumn{3}{|c|}{0.0290747} & \multicolumn{2}{|c|}{0.6371} \\
\hline $\mathrm{AF}$ & \multicolumn{3}{|c|}{0.00291796} & \multicolumn{2}{|c|}{0.0083} & \multicolumn{3}{|c|}{0.0277995} & \multicolumn{2}{|c|}{0.0003} \\
\hline Initial & \multicolumn{3}{|c|}{0.0000319886} & \multicolumn{2}{|c|}{0.0002} & \multicolumn{3}{|c|}{0.00967778} & \multicolumn{2}{|c|}{0.0023} \\
\hline Source & $S S$ & $D F$ & $M s$ & $F$-value & $\operatorname{Prob}>F^{*}$ & $S S$ & $D F$ & $M s$ & $F$-value & $\begin{array}{l}\text { Prob }>F \\
*\end{array}$ \\
\hline Model & 0.122156 & 5 & 0.0244313 & 8.86 & 0.0019 & 0.503947 & 5 & 0.100789 & 8,63 & 0,0021 \\
\hline Residue & 0.0275593 & 10 & 0.00275593 & & & 0.11673 & 10 & 0.011673 & & \\
\hline $\begin{array}{l}\text { Total } \\
\text { (Corr.) }\end{array}$ & 0.149716 & 15 & & & & 0.620677 & 15 & & & \\
\hline
\end{tabular}

*Significant at Prob $>F$ less than 0.05 . 
570 Highlights

571 - Novel route of anthracene oil-based pitches preparation in microwave heating

572 - Detailed characterization of pitches including the thermogravimetric analysis

573 - Microwave air-blowing process evaluated by means of a statistical analysis

574 - Evaluation of energy benefits of microwave heating when compared to conventional one 575 